\title{
Fish community structure and ecological degradation in tropical rivers of India
}

\author{
D.Chakrabarty and S. K. Das
}

\begin{abstract}
Chakrabarty, D. and Das, S. K. 2006. Fish community structure and ecological degradation in tropical rivers of India. - Web Ecol. 6: 27-36.
\end{abstract}

\begin{abstract}
Fish community structure and water chemistry of two tropical rivers of West Bengal, an eastern province of India, were studied for two annual cycles (January 2003-December 2004). Water quality and fish community structure reflected a higher degree of pollution in the Churni river than in the Jalangi river. We observed that $63.6 \%$ of fish species had disappeared from the polluted Churni river in $20 \mathrm{yr}$. For protection of fish biodiversity and enhancement of fish production, a rational management program should be implemented in Churni river.
\end{abstract}

D.Chakrabarty (debajyoti_chakrabarty@yahoo.co.in), Dept of Zoology, Krishnagar Government College, Krishnagar-741101, Nadia, West Bengal, India. - S. K. Das, Environmental Science Dept, Netaji Subhas Open Univ., 1, Wood Burn Park, Kolkata-700020, India.

In rivers, fish community structure is a good indicator of environmental stress (Barrella and Petrere 2003), because the composition of particular groups in fish communities reflect the level of habitat degradation (Wichert and Rapport 1998). Fish communities in rivers are particularly sensitive to pollution and overexploitation, and in this context rivers Churni and Jalangi, in the Nadia District (West Bengal, Fig. 1) are an interesting case study. The Jalangi river is situated ca $25 \mathrm{~km}$ north of the Churni river. Both share the same climatic conditions and had similar fish communities 22 yr ago (Chakrabarty 1983). Over the last years, however, the Churni river has suffered continuous episodes of water pollution and ecological degradation (Ghosh and Konar 1991) which may have led to a loss of species. Both rivers have an almost similar annual discharge (IWMED 2002), and may be seen as twin branches of the Padma river which ultimately discharges into the Ganges (Fig. 1). These two rivers are prominent in West Bengal since they are the major source of surface water, income for thousands of fishermen, and provide food to nearby 0.3 million people of the adjacent towns of Ranaghat and Krishnagar.

In this paper we describe the fish assemblages in these two rivers of contrasted characteristics, their environmental conditions, and the consequences of anthropogenic activities.

\section{Study area}

The Churni river is a tributary of the Padma river which originates in Bangladesh and flows for ca $95 \mathrm{~km}$ on Indian land. It is subjected to different anthropogenic activities throughout its course. The upper stretches receive discharges of sugar mill effluents from Darshana (Bangladesh), whereas the lower stretch in India is subjected to water obstruction by bamboo-made barrages in several places, industrial effluents and city sewage. The catchment area of this river includes the medium-populated $(0.14$ million) Ranaghat municipality $\left(23.11^{\circ} \mathrm{N}, 88.37^{\circ} \mathrm{E}\right)$. The opposite bank of this river comprises residential areas and 


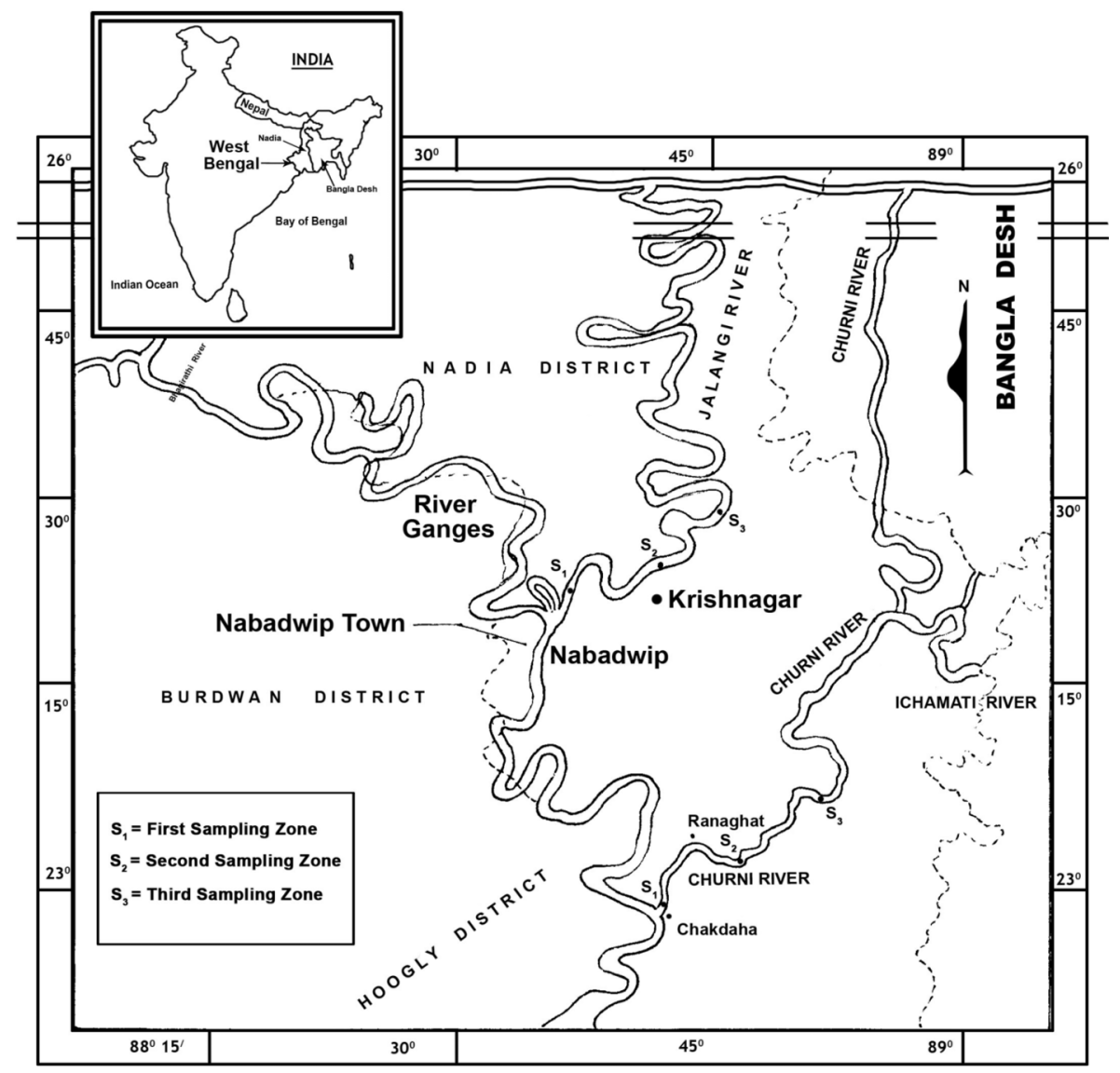

Fig. 1. Geographical location of the two studied rivers.

unorganized small-scale industries, which release their untreated effluents into the river (ca $24000 \mathrm{ld} \mathrm{d}^{-1}$ ). The river discharges into the Ganges near Chakdaha.

The Jalangi river flows from the western boundary of the Nadia District and crosses the city of Krishnagar $\left(23^{\circ} 24^{\prime} \mathrm{N}, 88^{\circ} 30^{\prime} \mathrm{E}\right.$, population of ca 0.15 million). It flows almost straight westwards, and discharges into the Ganges at Nabadwip (IWMED 2002). There are no large industries in the municipality, except Krishnagar State Dairy, which discharges ca $18000 \mathrm{l} \mathrm{d}^{-1}$ of processed water into the river. People residing near the eastern bank of the river use the water for recreational purposes.

\section{Water quality}

An approximate $15-\mathrm{km}$ stretch of rivers Churni and Jalangi were selected for sampling in order to address the pollution impact of Ranaghat and Krishnagar cities. All industrial facilities were located within this area. Three sampling zones, ca $5 \mathrm{~km}$ apart, were selected upstream, midstream and downstream for each river (Fig. 1). Each zone consisted of three sampling sites; two opposite river banks and midstream, labeled as east (E) besides township, middle (M), and west (W) opposite to township. Results within a zone are expressed as the mean of the three sites.

Water samples were collected monthly between 9 am and $11 \mathrm{am}$ from lotic zones at a depth of $5 \mathrm{~cm}$ from the surface. They were saved in 2 litre plastic containers for physico-chemical analysis, and also collected in sterilized glass tubes for bacteriological analysis in the laboratory following Standard methods (2002).

Temperature and $\mathrm{pH}$ were measured immediately after collection. Physico-chemical analysis of conductivity, dissolved oxygen (DO), initial biological oxygen demand (BOD), total dissolved solids (TDS), alkalinity, hardness, phosphorus, and total nitrogen, were performed in the laboratory on the same day or within a week. All analyses were done following the methodology outlined in Standard methods (2002) and in Wetzel and Likens (2004). 


\section{Fish community data}

At each sampling site, fish were collected at weekly intervals and species identified using a pre-tested, structured interview to local fishermen at fish landing stations along $70 \mathrm{~km}$ in both rivers. Fish were identified when collected by local fishermen. The nets used for fishing were gill or drag net with floaters and sinkers. The gill nets used were $200 \mathrm{~m}$ in length and $12 \mathrm{~m}$ in width. The net easily reached the river bottom and covered the length between the two banks. The sampling efforts were similar in all zones. A number of representative trapped fish were fixed in formalin and transported to the laboratory for study. A set of indicators such as weight, habitat orientation, and trophic structure were examined.

\section{Trophic structure}

Species in a fish community can be classified into trophic groups based on feeding habits (Karr et al. 1986, OEPA 1987). By analyzing the gut content we distinguished four types of trophic level, namely planktivore (PL), benthic feeder $(\mathrm{BE})$, omnivore $(\mathrm{OM})$, and carnivore (CA) (Table 1). The trophic level score (Gauch 1982, Wichert and Rapport 1998) denotes the relative frequency of the fish using the particular trophic level among all the trophic levels available in the system. E.g. the score in the Churni river for four species of planktivorous fish out of a total of 16 species would be obtained by dividing 4 by 16 and multiplying the result by 100 .

\section{Habitat orientation}

Fish were classified into three generic groups attending to habitat orientation: pelagic $(\mathrm{P})$, generalist $(\mathrm{G})$ and benthic (B) (Jhingran 1997). Habitat orientation score (Gauch 1982, Wichert and Rapport 1998) denotes the relative frequency of fish using the particular habitat among all available habitat in the system. The mean score of habitat orientation was compared between the two rivers.

\section{Similarity and dissimilarity indices}

Sorensen's coefficients (SC) were calculated between for the two rivers to identify the most likely indicator species of pollution (Gauch 1982, Benson and Magnuson 1992, Odum and Barrett 2005). Sorensen's coefficient (SC) measures similarity between two habitats:

$$
S C=2 a /(2 a+b+c)
$$

where $\mathrm{a}$ is the number of species common to the two habitats, $\mathrm{b}$ is the number of species present in habitat $\mathrm{B}$ but absent in habitat $A$, and $\mathrm{c}$ is the number of species present in site A but absent in site B. The index value varies between 0 and 1 . Zero indicates no similarity and 1 indicates maximum similarity.

An additional composition attribute was the Bray-Curtis dissimilarity index (BCD), a coefficient which is a robust and ecologically meaning index of changes in species composition (Faith et al. 1987, Legendre and Legendre 1998). BCD was calculated for taxa $(n=44)$ and abundance (standardized using $\log _{10}(\mathrm{X}+1)$ transformation; Legendre and Legendre 1998).

Bray-Curtis (B) is a measure of dissimilarity; hence 1-B is taken as a measure of similarity. This index varies between 0 and 1 .

$$
\mathrm{B}=\frac{\Sigma\left|\mathrm{X}_{\mathrm{ij}}-\mathrm{X}_{\mathrm{jk}}\right|}{\Sigma\left|\mathrm{X}_{\mathrm{ij}}-\mathrm{X}_{\mathrm{jk}}\right|}
$$

where $X_{i j}=$ number of individuals of ith species in sample or habitat or community $\mathrm{j}, \mathrm{X}_{\mathrm{ik}}=$ number of individuals of ith species in sample or habitat or community $\mathrm{k}$.

\section{Results}

\section{Water quality}

Mean water temperature and $\mathrm{pH}$ were very similar in both rivers (Fig. 2a). The dissolved oxygen content in Churni river water remained at ca $5 \mathrm{mg} \mathrm{l}^{-1}$ for most of year (November-May). During the October monsoon season, however, the organic matter contained in runoff water decreased it to $3 \mathrm{mg} \mathrm{l}^{-1}$ (Fig. 2b), which is at or near the limit for aquatic life (Jhingran 1997). This DO drop indicated the presence of substantial amounts of dissolved organic matter in the water. By contrast, the Jalangi river water remained saturated with dissolved oxygen most of the year (Fig. 2b). Slight reductions in oxygen concentration were observed during the monsoon (Jun-Aug) months. The average level of BOD was high in the case of river Churni (Fig. 2b), but the seasonal variation in the two rivers was to some extent similar. Both were affected by the occasional addition of degraded or partially degraded organic substances from the banks through erosion.

The mean level of hardness in Churni river was higher than in the Jalangi during for the study period and showed a similar seasonal trend (Fig. 2c). The variation in total alkalinity showed a trend similar to that of hardness (Fig. 2c).

The values of total solids were almost similar in the two rivers (Fig. 2d). The water from Churni river experienced its peak in conductivity values in April while Jalangi had its peak in March. However no definite seasonal trend was found in the two rivers regarding conductivity values (Fig. 2d). The highest differences between the two rivers were observed from July to November during the study period. 


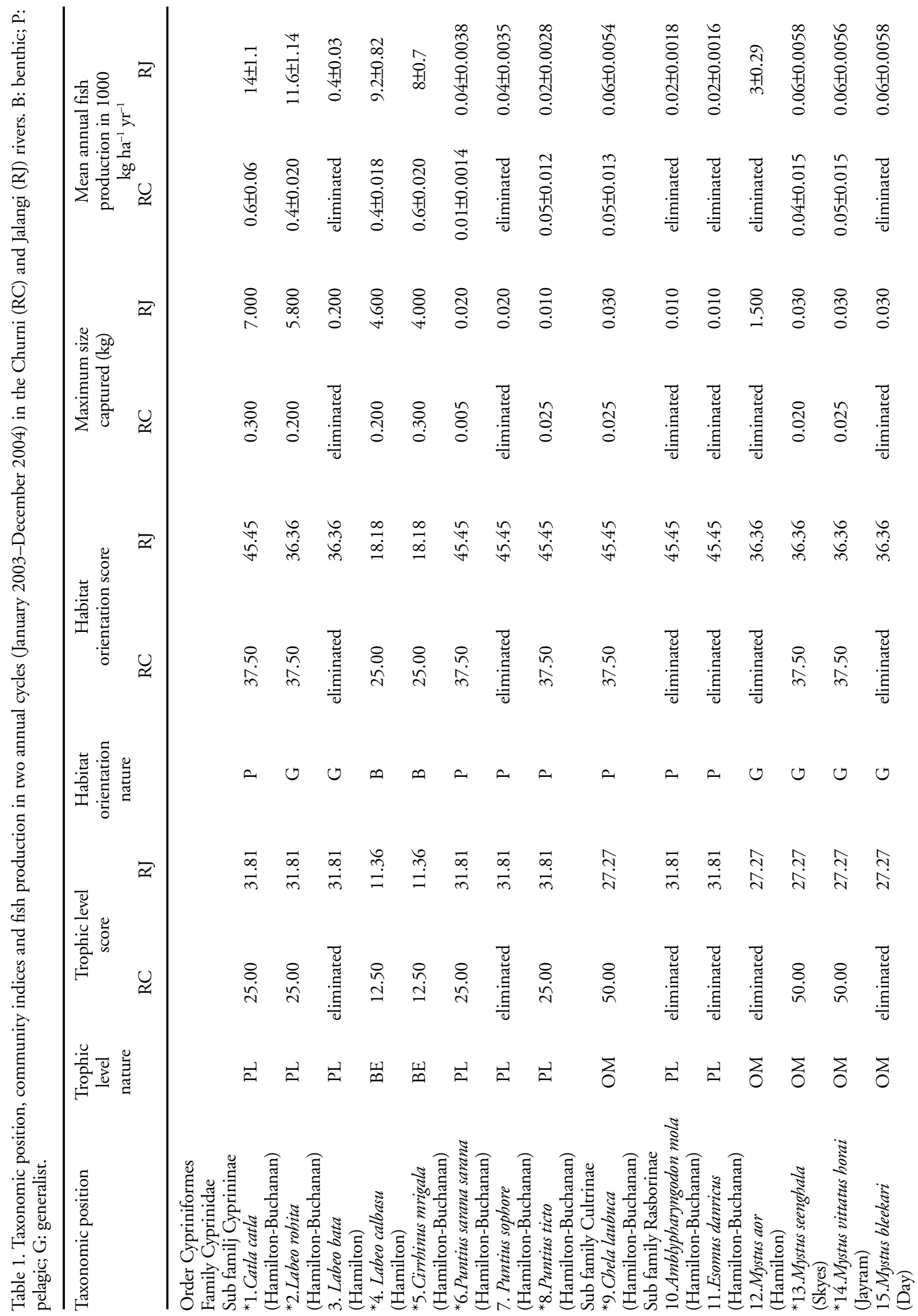




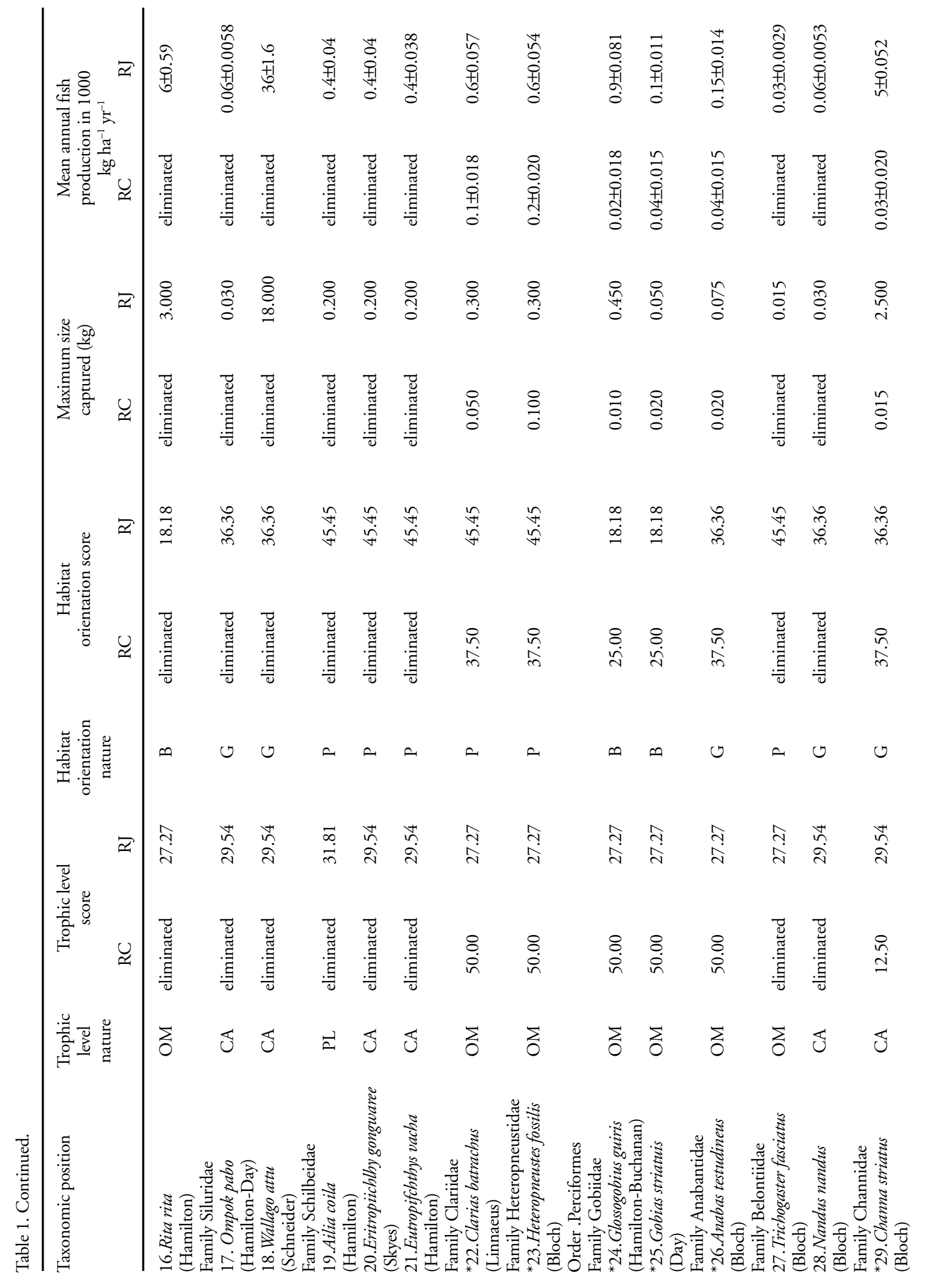




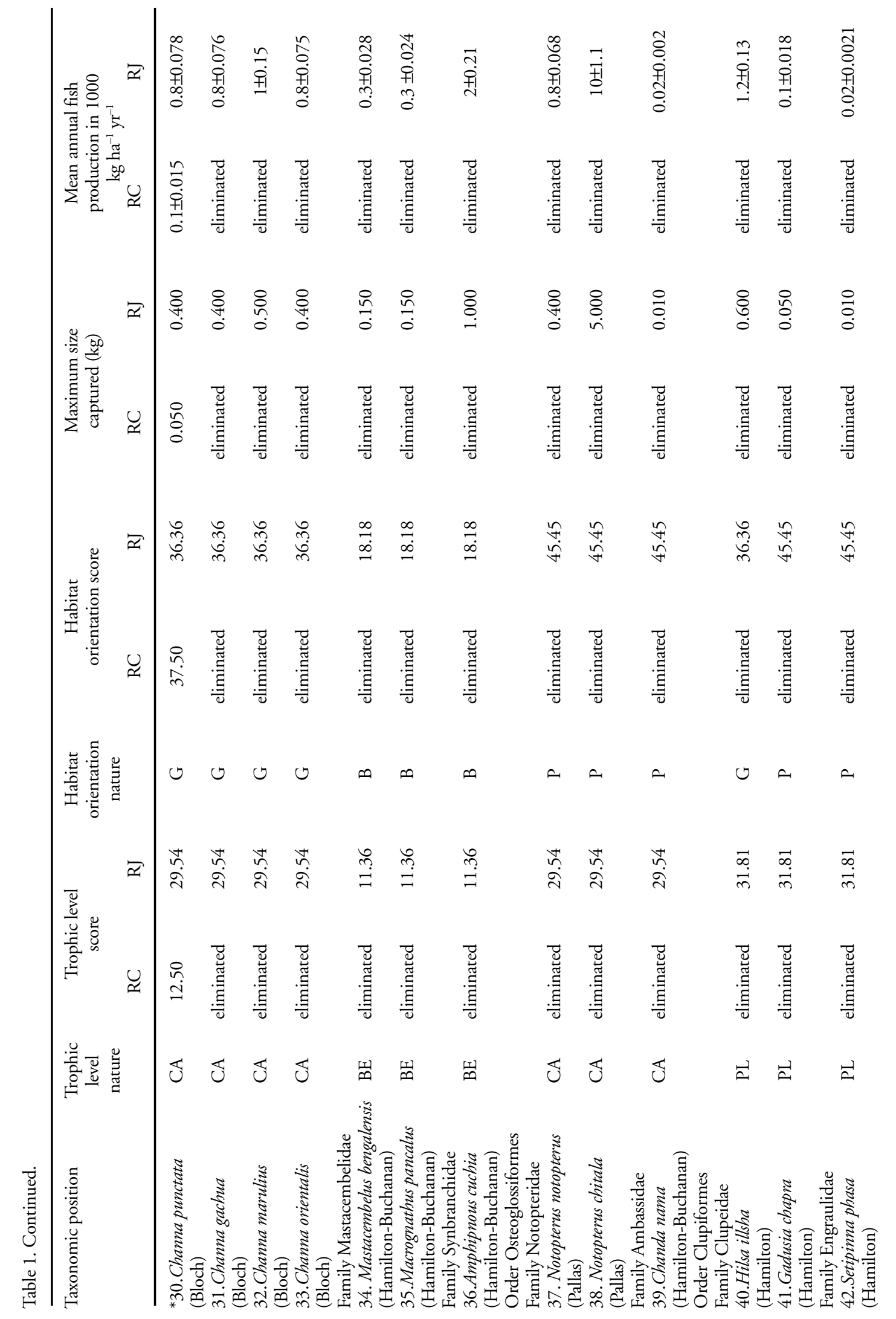




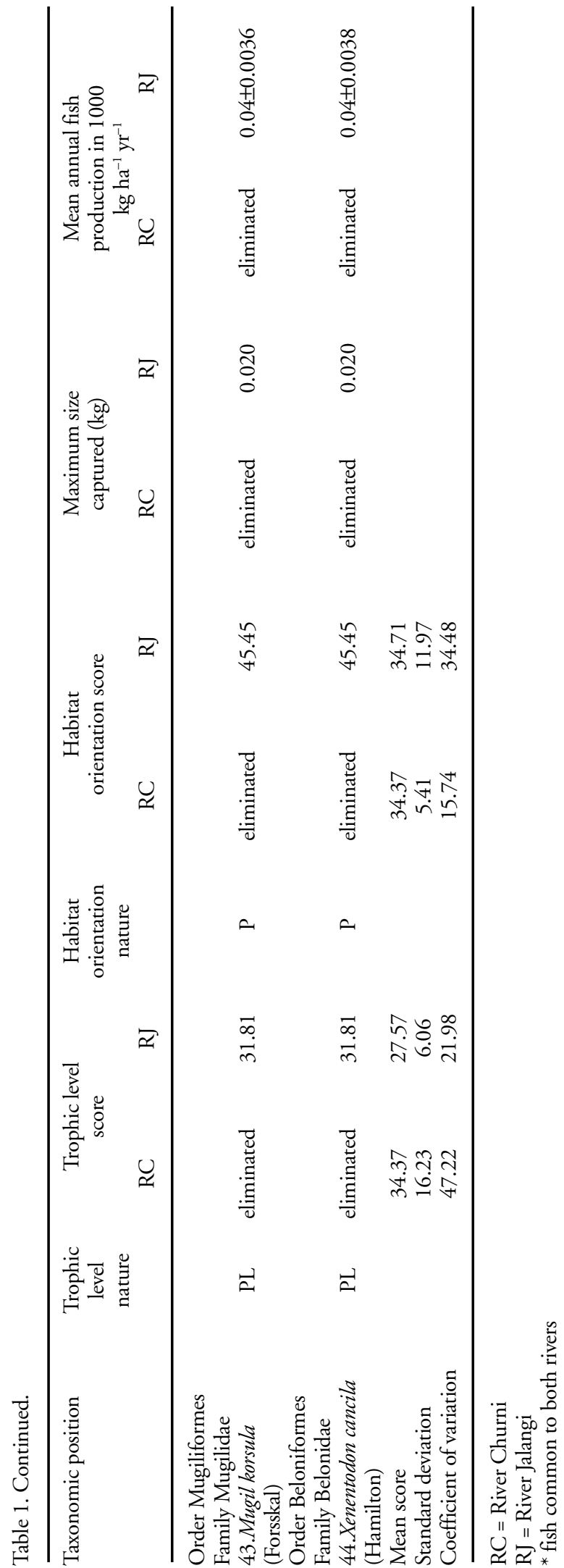

The level of total nitrogen and total phosphorus in the Jalangi river was considerably lower than in the Churni river (Fig. 1e).

A t-test $(p<0.001)$ denoted significant differences between both rivers in the concentration of $\mathrm{DO}, \mathrm{BOD}$, total-P, total-N, total alkalinity and conductivity throughout the year. Significant differences $(\mathrm{p}<0.001)$ were also found in total coliform counts between March and October (Fig. 2f). These data revealed that the Churni river was more contaminated with bacterial (MPN) than the Jalangi river, which was possibly caused by discharges of untreated sewage into the Churni river.

\section{Fish communities}

Fish data in 1983 indicate similar communities in both rivers, each represented by 44 different species. While the Jalangi river today still contains the same number of species, only 16 are found in the Churni river.

The mean score for habitat orientation (34.71 for Jalangi and 34.37 for Churni) showed no differences between the two rivers (Table 1). The mean trophic level score for the fish in Churni (34.37) was 124\% higher than that for the Jalangi (27.57). A t-test for trophic level score for common fish species showed significant differences between the rivers $(\mathrm{p}<0.001)$. This indicates that the fish community of the Churni river was likely responding to ecosystems pollution, resulting in the degradation of community structure compared to the Jalangi river. However, the diversity of fish present in the two rivers was markedly different as the Churni has 2.75 times fewer fish species than the Jalangi. Fish production was also reduced, being 18.75 times lower in the Churni river than in the Jalangi (Table 1).

The similarity index (Sorensen's coefficient) showed its lower value (0.266) and the dissimilarity index (Bray-Curtis) its maximum value (0.733) for carnivorous species (Table 2) among the four trophic levels. The dissimilarity index of trophic levels indicated that carnivore species (Table 2 ) had the highest score (> 0.733) in this study.

\section{Discussion}

The dissolved organic load is likely cause for concern in the Churni river, which regularly receives untreated municipal and industrial sewage. The excess in phosphorus may trigger proliferation of nitrogen-fixing algae, thereby enhancing the state of eutrophication and biodiversity loss.

Comparing fish biodiversity in the two rivers, we found 16 species common to both rivers and other 28 species present only in the Jalangi river that had disappeared in the Churni river. Among the taxa living in the Churni river, six are species commercially grown in nearby towns (serial number 1, 2, 3, 4, 15 and 16 in Table 1). The oldest of 


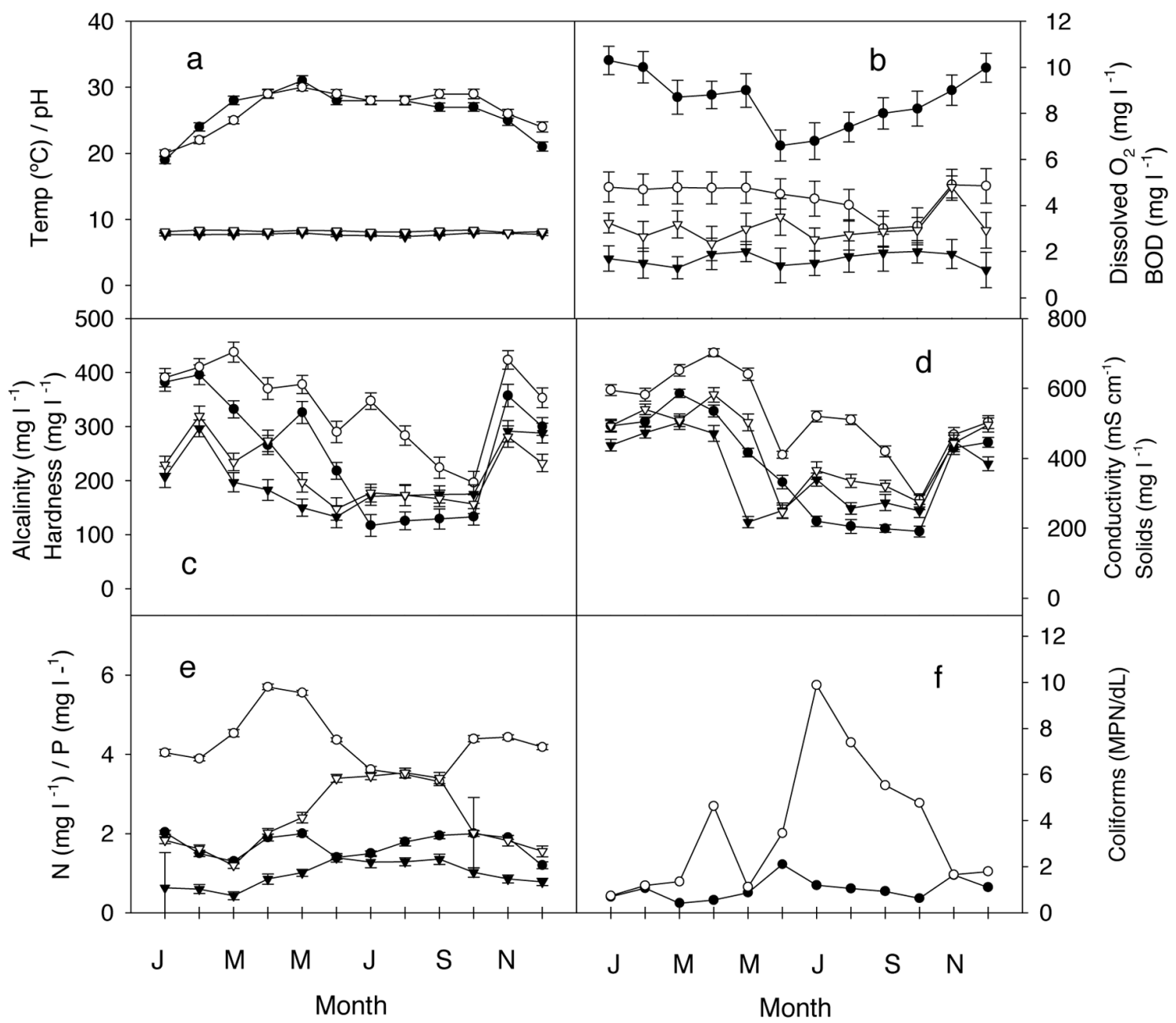

Fig. 2. Monthly means of environmental data in rivers Jalangi (solid symbols) and Churni (open symbols) in NE India. (a) Water temperature (circle) and pH (triangle). (b) Dissolved oxygen (circle) and biological oxygen demand (triangle). (c) Alcalinity (circle) and hardness (triangle). (d) Electrical conductivity (circle) and total solids (triangle). (e) Total nitrogen (circle) and phosphorus (triangle). (f) Coliforms. Standard errors shown when larger than symbol.

these fish captured in the river Churni was less than one year in almost all the cases (Table 1), as calculated from mass and size (Jhingran 1997). This indicates that these fish entered the river system during the rainy season, when nearby ponds are flooded and connected with the river bed through channels. The remaining ten species (Table 1) are not commercially grown and thus are native species resistant to pollution. The analysis of similarity index for trophic level showed that carnivore species (Table 2) were underrepresented with a score close to $0(>0.266)$ and thus can be used as an indicator taxon of pollution.

The mean trophic level score in the Churni river was $124 \%$ higher than in the river Jalangi, which indicates that fish communities in the latter were altered by ecosystems stress (Rapport 1995), resulting in the degradation of community structure compared to the Churni river. On the contrary, the high diversity of fish species in Jalangi river represents a variety of suitable habitat and food supplies capable of supporting many different species (Washington 1984). The habitat orientation score did not appear to be a useful indicator of ecosystem stress in lotic systems, as shown by Wichert and Rapport (1998).

From the analysis of fish trophic level, it appears that omnivores are the most tolerant to degradation or ecosystem dysfunction because they are able to use food from a wide variety of sources in a changing ecosystem (Wichert and Rapport 1998). Other trophic levels are more sensitive to degradation and include, in reverse order, planktivores, benthic insectivores (i.e. benthic feeders) and insectivores/ piscivores, i.e. carnivores at the top of the trophic structure (Karr and Dudley 1981). In the least disturbed systems, present species would belong to the benthic feeders and 
Table 2. Data regarding trophic level, habitat orientation, similarity and dissimilarity indices.

\begin{tabular}{|c|c|c|c|c|c|}
\hline \multirow{2}{*}{$\begin{array}{l}\text { Ecological } \\
\text { characteristics }\end{array}$} & \multirow[b]{2}{*}{ River } & \multicolumn{2}{|c|}{ Trophic level } & \multicolumn{2}{|c|}{ Habitat orientation } \\
\hline & & Churni & Jalangi & Churni & Jalangi \\
\hline Occurrence of fish species & & $\begin{array}{c}\mathrm{PL}=4 \\
\mathrm{BE}=2 \\
\mathrm{OM}=8 \\
\mathrm{CA}=2\end{array}$ & $\begin{array}{c}\mathrm{PL}=14 \\
\mathrm{BE}=5 \\
\mathrm{OM}=12 \\
\mathrm{CA}=13\end{array}$ & $\begin{array}{l}P=6 \\
G=6 \\
B=4\end{array}$ & $\begin{aligned} \mathrm{P} & =20 \\
\mathrm{G} & =16 \\
\mathrm{~B} & =8\end{aligned}$ \\
\hline Total & & 16 & 44 & 16 & 44 \\
\hline Similarity index & & \multicolumn{2}{|c|}{$\begin{array}{l}\mathrm{PL}=0.444 \\
\mathrm{BE}=0.571 \\
\mathrm{OM}=0.80 \\
\mathrm{CA}=0.266\end{array}$} & \multicolumn{2}{|c|}{$\begin{array}{l}P=0.461 \\
G=0.545 \\
B=0.666\end{array}$} \\
\hline Dissimilarity index & & \multicolumn{2}{|c|}{$\begin{array}{c}\mathrm{PL}=0.555 \\
\mathrm{BE}=0.428 \\
\mathrm{OM}=0.200 \\
\mathrm{CA}=0.733\end{array}$} & \multicolumn{2}{|c|}{$\begin{array}{l}P=0.538 \\
G=0.454 \\
B=0.333\end{array}$} \\
\hline
\end{tabular}

$\mathrm{PL}=$ Planktivores, $\mathrm{BE}=$ Benthic feeder, $\mathrm{OM}=$ Omnivore, $\mathrm{CA}=$ Carnivore

$\mathrm{P}=$ Pelagic, $\mathrm{G}=$ General, $\mathrm{B}=$ Benthic.

carnivores groups in a proportion higher than at degraded sites. As degradation intensifies, species at the top of the trophic structure would disappear first, followed by benthic insectivores, general insectivores, planktivores and omnivores (Wichert and Rapport 1998). In Churni river only two carnivore species were found, against thirteen species in Jalangi river. The dissimilarity index for carnivore species (Table 2) also supports the idea that these species can be used as indicators of pollution.

In conclusion, some structural properties of fish communities in the Churni river changed between 1983 and 2003. These changes appear to be related to anthropogenic activities and industrial practices. Detailed studies are required to quantify these changes and predict future action plans to monitor further loss of aquatic biodiversity.

Acknowledgements - The authors are grateful to B. Roy, Assistant Professor of Statistics, Krishnagar Govt. College, for his valuable suggestions.

\section{References}

Barella, W. and Petere, M. 2003. Fish community alterations due to pollution and damaging in Tiete and Paranapanema Rivers (Brazil). - River Res. Applic. 19: 59-76.

Benson, B. J. and Magnuson, J. J. 1992. Spatial heterogeneity of littoral of fish assemblages in lakes: relation to species diversity and habitat structure. - Can. J. Fish. Aquat. Sci. 49: 1493-1500.

Chakrabarty, D. 1983. Fin fish diversity in two tropical rivers of eastern India. - Unpubl. report, Kalyani, India.
Faith, D. P., Minchin, P. R. and Belbin, L. 1987. Compositional dissimilarity as a robust measure of ecological distance. Vegetatio 69: 57-68.

Gauch, H. G. 1982. Multivariate analysis in community ecology. - Cambridge Univ. Press.

Ghosh, T. K. and Konar, S. K. 1991. Effect of dye factory effluent on bottom biota of the River Churni. - Environ. Ecol. 9: 154-162.

IWMED (Inst. of Wetland Management and Ecological Design). 2002. Final report on water quality monitoring of Churni River at Ranaghat and Jalangi River at Krishnagar. West Bengal Pollution Control Board, Salt Lake City, Kolkata, India.

Jhingran, V. G. 1997. Fish and fisheries of India, 2nd ed. - Hindustan Publ. Corporation, Delhi.

Karr, J. R. and Dudley, D. R. 1981. Ecological perspective on water quality goals. - Environ. Manage. 5: 55-68.

Karr, J. R. et al. 1986. Assessing biological integrity in running waters: a method and its rationale. - Illinois Natural History Survey Special Publ. 5, Urbana, IL.

Legendre, P. and Legendre, L. 1998. Numerical ecology, 2nd ed. - Elsevier.

Odum, E. P. and Barett, G. W. 2005. Fundamentals of ecology, 5th ed. - EWP, Thomson/ Brooks.

OPEA 1987. Biological criteria for the protection of aquatic life. Vol. III. - Ecological Assessment Section, Division Water Quality, planning and Assessment, State of Ohio Environmental Assessment Agency.

Rapport, D. J. 1995. Ecosystem health: an emerging integrative science. - In: Rapport, D. J., Gaudet, C. L. and Callow, P. (eds), Evaluating and monitoring the health of large-scale ecosystems. Springer, pp. 5-31.

Standard methods 2002. Standard methods for the examination of water and waste waters, 21st ed. - American Water Works Association (AWWA), Water Pollution Control Federation 
(WPCF) and American Public Health Association (APHA) Washington DC, USA.

Washington, H. G. 1984. Diversity, biotic and similarity indices: a review with special relevance to aquatic ecosystem. - Water Res. 18:, 653-694.

Wetzel, R. G. and Likens, G. E. 2004. Limnological analysis, 3rd ed. - Springer.
Wichert, G. A. and Rapport, D. J. 1998. Fish community structure as a measure of degradation and rehabilitation of riparian systems in an agricultural drainage basin. - Environ. Manage. 22: 425-443. 